\title{
Stress management training and gratitude journaling in the classroom: an initial investigation in Indian context
}

\author{
Pulkit Khanna ${ }^{1} \cdot$ Kamlesh Singh ${ }^{2}$ \\ Accepted: 26 November 2020 / Published online: 8 January 2021 \\ (C) The Author(s), under exclusive licence to Springer Science+Business Media, LLC part of Springer Nature 2021
}

\begin{abstract}
Stress and allied difficulties are pervasive among school students in present times. This concern is further magnified in the Indian context with the large represention of young people in the population and limited resources to match. The present study aimed to evaluate the impact of a classroom based stress management training and gratitude journaling intervention (Flinchbaugh et al., 2012) among Indian adolescents. The intervention curriculum was adapted to suit the study context. A total of 238 students (57\% males) from Grades 7-9 participated in this study. Participants were recruited from two schools, and their age ranged from 11 to 14 years. In each participating school, students were randomised at the classroom level into three intervention groups (Stress Management Training, Gratitude Journaling, combination of both), and one control group. Using a pre-test - post-test design, intervention impact on measures of well-being, life satisfaction, perceived stress, meaning, and engagement in the classroom was evaluated. Results suggested limited effectiveness of stress management training and gratitude journaling among participants in the present context. Plausible explanations for these findings are discussed. The study emphasizes the need for customised interventions to obtain optimal outcomes among diverse populations.
\end{abstract}

Keywords Adolescents $\cdot$ Stress management $\cdot$ Gratitude journaling $\cdot$ Well-being

\section{Introduction}

The growing menace of stress and allied problems in young people across the globe has been extensively studied (e.g. Kieling et al., 2011; Patel et al., 2007; Wilhsson et al., 2017). Patton et al. (2016) described the unparalleled influences impacting the health and well-being of the most sizeable generation of 10 to 24 year old people across the world. Among youth, adolescents are particularly vulnerable to experience intense stress pertaining to academic performance, fitting in with peers, and body image issues among other concerns (Neff \& McGehee, 2010). Further, it is important to note that majority of the world's adolescent population resides in low- and middle-

Pulkit Khanna

pulkitkhanna.iitd@gmail.com

Kamlesh Singh

singhk.iitd@gmail.com

1 Jindal Institute of Behavioral Sciences, O.P. Jindal Global University, Haryana, India

2 Department of Humanities \& Social Sciences, Indian Institute of Technology Delhi, New Delhi, India income environments, imperiled by various psychosocial concerns (Fisher et al., 2011). The alarming global trends of stress among adolescents are also mirrored in India, which is home to over 250 million adolescents, accounting for one-fifth of the world's adolescent population (Office of the Registrar General \& Census Commissioner India, 2011). According to the Gururaj et al. (2016), over 13\% of adolescents in metropolitan India suffered from mental morbidity.

Numerous localized studies from different regions of India convey a similar story. Over $45 \%$ school students in Chandigarh were found to suffer from stress (Arun \& Chavan, 2009). According to another study, the prevalence of depression, anxiety, and stress was $65.53 \%, 80.85 \%$, and $47.02 \%$, respectively among school going adolescents in Chandigarh (Sandal et al., 2017). A study on Amritsar based male adolescents reported that $39.6 \%$ of participants were stressed (Chhabra \& Sodhi, 2011). The studies enlisted so far were located in North India. Working with adolescents from Gujarat (Western India), Nair et al. (2017) reported that at least one in eight study participants was at risk of mental health problems. Based on their cross-sectional study among high school students in North-East India, Kumar and Akoijam (2017) reported widespread depression, anxiety, and stress among participants. Studies among school going adolescents 
from South India too reported widespread prevalence of depression and anxiety (Jayashree et al., 2018), as well as stress, and the need for resilience building programs among students (Prabhu \& Shekhar, 2017). This brief review is intended to offer a glimpse of the widespread nature of mental health concerns among young people across different parts of India. In fact, a meta-analytic study by Malhotra and Patra (2014) suggests the existence of significant mental health morbidity in over $23 \%$ of Indian school samples.

This rampant prevalence of stress among Indian students has been attributed to various factors. Deb et al. (2015) described academic stress, parental pressure, anxiety, and mental health as prominent concerns among Indian high school students. While studying the contextual influences on stress among adolescents in urban India, Parikh et al. (2019) identified persistent academic pressure, parental aspirations, and fast-paced social changes among some contributing factors. Immediate social contexts including family, school, and peers have also been considered as significant factors in inducing stress among Indian adolescents (Parikh et al., 2019). In another study, Rentala et al. (2019) identified academic stress as the leading stressor among Indian adolescent girls. Parikh et al. (2019) advocate the need to gain insight into contextual aspects in order to provide relevant and feasible solutions for low resource settings such as India.

\section{Interventions to Alleviate Stress and Boost Well-Being in Students}

In view of widely prevalent stress and associated adverse outcomes in students, the need has been felt world over for broad based programs that inculcate in children and adolescents the willingness to seek help, boost resilience, nurture emotional regulation, and interpersonal skills (Flett \& Hewitt, 2013). Patton et al. (2016) emphasize that proactive identification and handling of mental health issues during adolescence can better long-term health outcomes. Towards this end, schools are regarded as a favorable setting to deliver interventions for mental health and well-being promotion (Fazel et al., 2014). Literature offers many examples of classroom-based positive psychological interventions to alleviate stress and enhance well-being among students. Of these, studies focusing on stress management training and gratitude journaling are relevant to this paper.

\section{Stress Management and Gratitude Journaling Interventions}

A plethora of programs centered on different stress management techniques including mindfulness, meditation, progressive muscle relaxation (PMR), and yoga among others have been evaluated among students. In educational settings, mindfulness interventions have been associated with enhanced calmness (Broderick \& Metz, 2009; Nidich et al. 2011), less stress, (Biegel et al., 2009; Edwards et al., 2014; Kuyken et.al, 2013), reduced depressive symptoms (Kuyken et.al, 2013; Lau and Hue, 2011; Liehr and Diaz, 2010), gains in optimism, social competence, and self-concept (Schonert-Reichl \& Lawlor, 2010), as well as improved academic outcomes (Nidich et al., 2011). Working with Indian adolescents, Anand and Sharma (2011) reported that an eight-week long Mindfulness-Based Stress Reduction (MBSR) program significantly reduced stress, emotional symptoms, and improved well-being among participants. Nair and Meera (2014) demonstrated that classroom-based PMR practiced daily over six weeks was effective in reducing academic stress among school students in India. Yoga-based interventions among students have also been positively associated with gains in health, cognitive ability, and positive affect (Vhavle et al., 2017), reduced tension and anxiety (Ferreira-Vorkapic et al., 2015), positive behaviors (Rashedi et al., 2020), and qualitatively perceived benefits in self-regulation, academic outcomes, and stress reduction (Wang \& Hagins, 2016). Interventions encompassing assorted techniques such as the multi-method stress management intervention (Keogh et al., 2006), relaxation response-based curriculum (Foret et al., 2012), and multiple stress management intervention (Chinaveh, 2013) have also shown favorable outcomes among students. On the other hand, many interventions in this area have also exhibited little or no effectiveness. Vierhaus et al. (2010) demonstrated the limited effectiveness of a school based stress prevention program among German adolescents. They found that the intervention effects were not stable once the program ended. Based on a PMR intervention among Malaysian students, Hashim and Zainol (2015) reported no significant gains in anxiety, depression, stress, and attention among participants. A pilot study of an Indian universitybased intervention by Wit et al. (2016) revealed initial decline in average stress among participants, which was not sustained at follow-up. Overall, Lohaus et al. (2001) concluded that the general use of relaxation techniques may be less effective as compared to their application for distinct medical conditions in children.

Based on their study among college undergraduates, Emmons and McCullough (2003) asserted that participants in a gratitude journaling condition reported higher wellbeing in comparison to groups that maintained a journal about neutral or negative life events. In another study involving young adolescents, Froh et al. (2008) reported that listing blessings (an exercise similar to gratitude journaling) led to greater optimism, life satisfaction, and less negative affect (as compared to listing hassles) among students. Shi and Zhu (2008) reported the effectiveness of a gratitude-focused intervention among Chinese middle school students. More recently, Isik and Ergüner-Tekinalp (2017) reported the benefits of gratitude journaling in augmenting gratitude, life satisfaction, 
and positive affect among Turkish college students. On the basis of their intervention study with undergraduate participants, Schnitker and Richardson (2018) demonstrated that formulating gratitude journaling as prayer resulted in better benefits in hedonic and eudaimonic well-being.

Although gratitude journaling is often associated with positive outcomes, it is noteworthy that there is evidence to suggest some limitations associated with the use of journaling among children. Some of these concerns include students feeling "journaled to death" (Dyment \& O'Connell, 2010, p. 234), and a general aversion to journal writing (Crème, 2005; Mills, 2008). Additionally, students may be hesitant to engage deeply with the process of journal writing, and may write casually if they don't fully trust the reader with their reflections (Dyment \& O'Connell, 2003; Epp, 2008). Dyment and O'Connell (2010) also highlighted the problem with assuming that students inherently know how to journal.

While many intervention studies have exclusively focused on either one, a few studies have incorporated both these techniques together. In one such example, Flinchbaugh et al. (2012) examined the effect of stress management techniques, gratitude journaling, a combination of these two, and a control condition among students from a management classroom. While Flinchbaugh et al. reported gains in perceived meaning and engagement in the classroom among participants from the combined intervention and gratitude journaling conditions, no significant effect was seen on life satisfaction or classroom specific stress. Hines and Scherer (2018) also examined the impact of mindful meditation and gratitude journaling on stress and well-being among college students and reported no signifcant effects. Notably, many of these studies were conducted in higher education settings, with relatively less work situated in schools. Further, majority of the published literature in the area of student well-being comes from Western and developed nations (Gilman et al., 2014), leaving much to be desired from non-western and Asian contexts such as India. Next, we discuss the rationale of the present study which field-tests a related intervention in Indian classrooms.

\section{Rationale of the Present Study}

There is dearth of a strong policy for child and adolescent mental health in India that could mitigate health-care expenditure and secure the future potential of Indian youth (Hossain \& Purohit, 2019). Nevertheless, Roy et al. (2019) affirmed the emerging focus on adolescent mental health in India. Yet constraints of financial and human resources continue to hinder the grass root level implementation of programs and policies. The Gururaj et al., 2016 reported a vast treatment gap ranging from $73.6 \%$ for severe mental disorders to $85 \%$ for common mental disorders. A pressing need exists for psychosocial interventions to augment Indian adolescents' repertoire of coping strategies
(Parikh et al., 2019). It then becomes pertinent to foster initiatives that bridge this gap (via both preventive and remedial mechanisms), in resource efficient as well as sustainable ways. The present study is rooted in the idea that while today's youth are faced with formidable concerns, schools have the potential to equip them with healthy coping skills, socio-emotional prowess, and set them on the path of long-term health (Tran et al., 2014). Further, research suggests the potential benefits of stress management training (e.g., Alborzkouh et al. 2015; Anand \& Sharma, 2011; Nair \& Meera, 2014; Rashedi et al., 2020) and gratitude journaling (e.g., Isik \&Ergüner-Tekinalp, 2017; Shi \& Zhu, 2008) for improved outcomes among students from varied backgrounds. The present study utilizes these promising techniques and represents a step towards addressing the need for well-being initiatives among Indian adolescents. By using an existing intervention module (Flinchbaugh et al., 2012) and field-testing it in a different cultural and demographic context, i.e. Indian school students, this study also contributes to the wider cause of intervention research.

The aim of this study was to assess the efficacy of a stress management and gratitude journaling intervention (Flinchbaugh et al., 2012) among Indian adolescent school students. It was hypothesized that participants in the intervention conditions (as compared to the control conditon) would experience significant gains on all favourable indices of wellbeing (overall mental well-being, positive affect, meaningfulness, engagement, and life satisfaction), and decline in the adverse indicators (stress, and negative affect).

\section{Method}

\section{Study Design and Setting}

A quasi-experimental design was used in the present sudy. The intervention involved weekly sessions spread over 8 weeks during normal school hours across eight classrooms in two schools. Participating classrooms were randomly designated to one of four conditions (three intervention groups, and one control). This process for randomisation at the level of classrooms (instead of individual students) has been endorsed by Collins et al. (2014) for studies involving students in a school setting. Participants completed the assessment measures at pre-test (Time 1) and post-test (Time 2), immediately before the first session, and after the last session respectively.

The present study emanates from a wider research project aimed at examining the efficacy of some positive psychological intervention programs in the Indian clasroom context. We approached twenty schools across North India and eight schools that agreed to participate in this overall research project were shortlisted. Considering the present study design and logistics, two of these schools that consented to run an 8-week 
long intervention program were chosen. Figure 1 exhibits the overall study set-up and design.

\section{Participants}

The study began with 250 students from two schools located in Chandigarh (a Union Territory in North India). Of these, 12 students $(4.8 \%)$ were dropped from analysis due to their absence during post-test assessment. Finally, data for 238 students from Grade 7 - Grade $9\left(M_{\text {Age }}=12.31\right.$ years, $S D=1.27$, age range: $11-14$ years) was considered. Participants included $57 \%$ males, $36 \%$ females, and the remaining $7 \%$ did not report their gender. They hailed predominantly from urban $(81 \%)$ and nuclear $(73 \%)$ households.

Indian nationality, and no diagnosed or pre-existing mental health concerns were kept in mind as inclusion criteria while recruiting participants. However, school authorities reported no cases from the selected classes that had to be excluded for this reason.

\section{Outcome Measures}

To evaluate the impact of the intervention exercises, we used the same outcome measures as Flinchabaugh et al. (2012), and one additional measure for overall well-being. Following Flinchbaugh and colleagues, adapted versions of scales for stress, meaningfulness and engagement were used to assess these variables in the classroom context. Students were provided handouts containing an informed consent form, demographic profile sheet and scales explained ahead.

Well-Being Mental Health Continuum - Short Form (MHC SF; Keyes, 2005) containing 14 items was used. It includes three, five, and six items to represent emotional well-being (EWB), social well-being (SWB), and psychological wellbeing (PWB) respectively, rated from 0 (Never) to 5 (Everyday). Sub-scores for EWB, SWB, PWB, and a composite mental well-being score were calculated. The scale has shown good internal consistency of $\alpha>.80$ (Keyes, 2005). In the present study, a subscale reliability ranging from $\alpha=.60$ to .69 and a total scale reliability of $\alpha=.80$ was obtained.

Life Satisfaction The 5-item Satisfaction with Life Scale (SWLS; Diener, Emmons, Larsen, \& Griffin, 1985), rated from 1 (Strongly Agree) to 7 (Strongly Disagree) was used to measure life satisfaction. The present study found $\alpha=.71$ for this scale.

Stress: An adapted version of the 10-item Perceived Stress Scale (PSS; Cohen, Kamarck, \& Mermelstein,1983) was used to measure students' classroom-specific stress. Participants rated each item on a scale of 1 (Always) to 7 (Never). The present study found $\alpha=.65$ for this scale.

Fig. 1 Flowchart of Overall Study Design

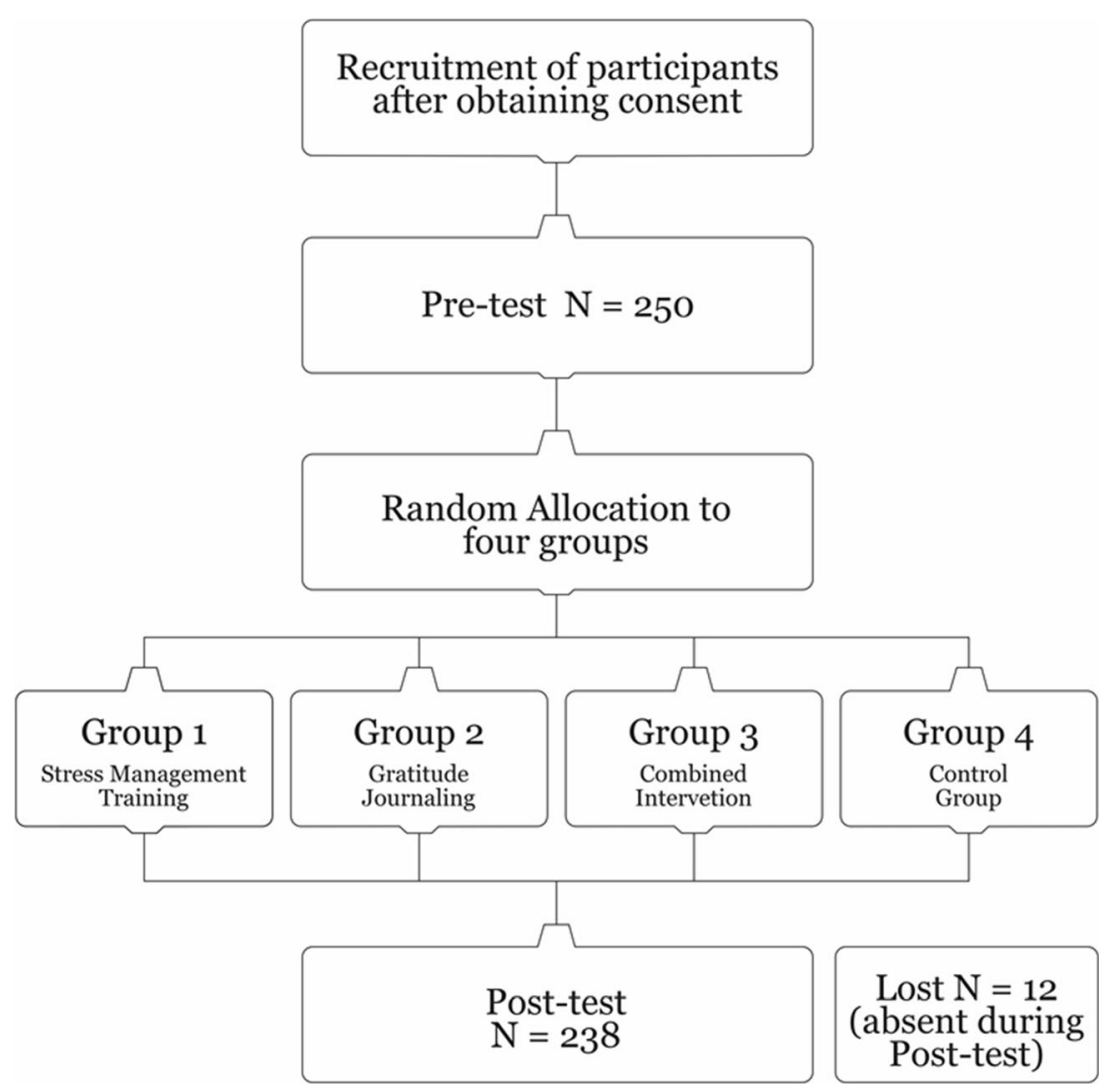


Meaningfulness Ten items adapted from May (2004) were used to measure meaningfulness in the classroom. Participants rated each item on a scale of 1 (Always) to 7 (Never). Scale reliability of $\alpha=.88$ was obtained in the present study.

Engagement Ten items from an existing scale of engagement (May, Gilson, \& Harter, 2004) were used to measure students' level of engagement in the classroom. Each item was rated on a scale of 1 (Strongly Agree) to 7 (Strongly Disagree). Total engagement score was obtained by adding all individual scores. Scale reliability of $\alpha=.68$ was obtained in the present study.

\section{Procedure}

\section{Background and Preparation}

As mentioned previously, this study emerged out of a wider research project. Consequently, all the outcome measures used herein were exclusive to this study, with the exception of MHC-SF (Keyes, 2005) that was common to other studies encompassed in this research project. Therefore, the psychometric properties of all measures used were computed on the present pre-test sample $(n=250)$, while those for MHC-SF were based on the all-inclusive sample $(n=1002)$.

Keeping in mind the participants' linguistic proficiency, all the material in this study was prepared bilingually (using English and Hindi). Towards this process, all questionnaires were first translated to Hindi. The Hindi transcripts were then evaluated by a panel of bilingual experts and subsequently back translated to English to establish appropriate translation. Detailed explanation and rationale for this process have been documented elsewhere (Khanna \& Singh, 2016, 2019).

At the outset, the researchers interacted with school authorities and obtained their approval for intervention delivery and data collection within the school classes. The first author visited participating schools to familiarise with the context and plan out the logistics, scheduling and other arrangements for intervention delivery. Thereafter, letters explaining the scope of the study and seeking active parental consent were sent home with the prospective student participants. Once parental consent was obtained, students completed informed consent forms in the classroom before pre-testing. They were informed of their right to withdraw from the study at any stage if they wished to.

\section{Intervention Implementation at School}

With help from the school staff, participating classrooms within each school were randomly allocated across four groups as per Flinchbaugh et al.'s (2012) study. These four groups were:
Stress Management Training (SMT) Participants were led through a new stress management technique every fortnight. Keeping in mind that these participants were younger students (as compared to undergraduates in Flinchbaugh et al.'s study), the facilitator visited the classroom every week; repeating each new technique in the subsequent session. Thus, two sessions were devoted to each stress management technique, namely deep breathing, progressive muscle relaxation, guided imagery, and positive self-talk (cf. Flinchbaugh et al., 2012). Standard instructions retrieved from web sources were used for each technique. Participants were guided about the proper way to practice each technique and its associated benefits. Thereafter, they were given time to practice in the classroom in the presence of the facilitator and also encouraged to partake these exercises independently in their spare time.

Gratitude Journaling (GJ) At the outset, a booklet titled ' $M y$ Gratitude Journal' was provided to each student in this group. Participants were instructed to label their journals and retain them for the next eight weeks. Every week, they were asked to write five things for which they felt grateful during the past week. This exercise was done within the classroom session; however participants were encouraged to maintain the journal beyond these sessions as well. The journals were collected at the end of the intervention.

Combined SMT and GJ (Combined Intervention) This group practiced a combination of both activities described previously. Participants were provided a booklet titled 'My Gratitude \& Stress Management Journal'. In addition to gratitude journaling, they were asked to reflect upon their use of stress management techniques. Students were instructed to maintain this journal throughout the intervention, after which it was collected.

Control Group (CG) Students in this group continued with their usual class routine and were involved only during data collection at Time 1 and Time 2.

Adaptation We largely followed Flinchbaugh et al. (2012) in terms of study design and curriculum delivery. However, given that this study was conducted with school going adolescents as opposed to management college students; and in a different cultural context, some important adaptations were introduced. These included modifications in overall program duration, as well as frequency of introduction of new stress management techniques in the classroom. Further, online journaling from Flinchbaugh's study was substituted by handwritten journals. Finally, the same facilitator (first author) worked with participants across all groups. Detailed explanation and rationale for these adaptations are provided in Appendix 1 Table 3. 


\section{Data Analysis Procedures}

To begin with, psychometric properties of all the scales used were validated in the present context. This was done via confirmatory factor analysis (CFA) using LISREL 8.8. Outcomes based on the CFA along with widely accepted values of all parameters considered in this study are presented in Appendix 2 Table 4. All other analyses were carried out using SPSS (Version 17). Based on missing value analysis, the missing values were found $<5 \%$ and random in nature. These were replaced by means of a regression analysis as per Tabachnick and Fidell's (2007) recommendation. Descriptive statistics were computed for all four intervention groups at pre-and post-test. Thereafter, baseline equivalence of groups was established through analysis of variance (ANOVA) comparing the four groups on variables of interest at pre-test. To examine intervention impact across the four groups, analysis of covariance (ANCOVA) was carried out on each dependent variable at post-test, taking the respective pre-test score as covariate. Wherever the ANCOVA revealed statistically significant Fvalues for a variable, subsequent pairwise comparisons using Bonferroni adjustment were computed to further compare the four group means. This was done to identify which pairs of groups were significantly different. Partial $\eta 2$ was also computed to assess the extent of variance accounted for by 'group'. Findings from these analyses are presented in the next section.

\section{Results}

The means and standard deviations across all four groups at pre-test (Time 1) and post-test (Time 2) are presented in Table 1 . To study the intervention effect, we considered data for 238 students $(n 1=60, n 2=60, n 3=58, n 4=60)$, allocated across three interventions and one control group. Results of the ANCOVA indicated significant overall effect on social well-being and overall well-being (as indicated by total MHC scores) at post-test; after controlling for corresponding pre-test scores. No significant overall effect was found on any of the other aspects of well-being, life satisfaction, stress, meaning, and engagement. An overview of these findings is presented in Table 2. We detail ahead the findings for the two variables in which significant overall effect was reported.

A significant overall effect in social well-being scores was obtained, $F(3,233)=4.28, p=.006$, partial $\eta 2=.05$. The mean scores for participants' social well-being at post-test, adjusted for the corresponding pre-test scores revealed the following sequence across the four groups: combined intervention $(M=16.94)$, control group $(M=16.19)$, stress management training $(M=15.21)$, and gratitude journaling $(M=14.36)$. Further pairwise contrasts using the Bonferroni correction revealed that the adjusted means for gratitude journaling were significantly different from the control group $(p=.01)$. No other significant pairwise comparisons were seen.

Further, ANCOVA revealed significant overall effect on overall well-being represented by scores on MHC Total, $F$ $(3,233)=2.97, p=.03$, partial $\eta 2=.04$. The mean scores for participants' overall well-being at post-test, adjusted for the corresponding pre-test scores were ordered across the four groups as follows: combined intervention $(M=50.75)$, control group $(M=48.68)$, stress management training $(M=47.65)$, and gratitude journaling $(M=45.86)$. Further pairwise contrasts using the Bonferroni correction revealed a significant difference only between gratitude journaling and control group $(p=.02)$. There were no other significant pairwise comparisons.

In a nutshell, we obtained significant effects only on two outcome variables - social well-being and overall well-being.

Table 1 Descriptive Statistics for All Four Groups at Pre-test and Post-test

\begin{tabular}{|c|c|c|c|c|c|c|c|c|}
\hline & \multicolumn{4}{|l|}{ Time 1} & \multicolumn{4}{|l|}{ Time 2} \\
\hline & $\begin{array}{l}\text { Group1 } \\
(n=60) \\
\text { Mean } \pm \text { SD }\end{array}$ & $\begin{array}{l}\text { Group } 2 \\
(n=60) \\
\text { Mean } \pm \text { SD }\end{array}$ & $\begin{array}{l}\text { Group } 3 \\
(n=58) \\
\text { Mean } \pm \text { SD }\end{array}$ & $\begin{array}{l}\text { Group } 4 \\
(n=60) \\
\text { Mean } \pm \text { SD }\end{array}$ & $\begin{array}{l}\text { Group1 } \\
(n=60) \\
\text { Mean } \pm \text { SD }\end{array}$ & $\begin{array}{l}\text { Group } 2 \\
(n=60) \\
\text { Mean } \pm \text { SD }\end{array}$ & $\begin{array}{l}\text { Group } 3 \\
(n=58) \\
\text { Mean } \pm \text { SD }\end{array}$ & $\begin{array}{l}\text { Group } 4 \\
(n=60) \\
\text { Mean } \pm \text { SD }\end{array}$ \\
\hline EWB & $10.8 \pm 2.98$ & $11.58 \pm 2.76$ & $10.57 \pm 2.75$ & $10.42 \pm 2.51$ & $10.93 \pm 2.02$ & $10.57 \pm 2.9$ & $10.57 \pm 2.87$ & $11.32 \pm 2.69$ \\
\hline SWB & $15.68 \pm 3.71$ & $16.43 \pm 3.69$ & $15.48 \pm 3.75$ & $14.33 \pm 4.14$ & $15.25 \pm 3.83$ & $14.55 \pm 4.49$ & $16.19 \pm 4.44$ & $16.7 \pm 4.04$ \\
\hline PWB & $21.15 \pm 4.38$ & $22.02 \pm 4.75$ & $20.9 \pm 5.16$ & $21.1 \pm 4.57$ & $21.47 \pm 5.18$ & $21.4 \pm 5.3$ & $21.74 \pm 4.97$ & $22.25 \pm 4.9$ \\
\hline MHC Total & $47.63 \pm 7.82$ & $50.03 \pm 8.34$ & $46.95 \pm 8.77$ & $45.85 \pm 9.44$ & $47.65 \pm 8.81$ & $46.52 \pm 10.2$ & $48.5 \pm 9.49$ & $50.27 \pm 8.74$ \\
\hline SWLS & $13.63 \pm 6.2$ & $15.38 \pm 5.8$ & $14.09 \pm 6.5$ & $15.37 \pm 6.79$ & $16.2 \pm 5.95$ & $15.03 \pm 7.09$ & $15.43 \pm 7.47$ & $14.73 \pm 6.02$ \\
\hline PSS & $38.72 \pm 7.94$ & $40.75 \pm 7.52$ & $36.66 \pm 7.7$ & $37.97 \pm 8.3$ & $41.25 \pm 8.73$ & $39.95 \pm 10.2$ & $41.47 \pm 6.7$ & $42.43 \pm 7.5$ \\
\hline Meaning & $25.27 \pm 11.21$ & $26.68 \pm 12.03$ & $26.9 \pm 12.95$ & $28.6 \pm 12.72$ & $24.47 \pm 12.22$ & $29.53 \pm 14.05$ & $26.81 \pm 11.92$ & $26.08 \pm 10.89$ \\
\hline Engagement & $29.72 \pm 12.25$ & $32.78 \pm 9.16$ & $33.47 \pm 8.58$ & $34.37 \pm 8.68$ & $30.18 \pm 9.58$ & $33.15 \pm 9.52$ & $32.86 \pm 8.67$ & $31.63 \pm 8.7$ \\
\hline
\end{tabular}

Note. Group 1 = Stress Management Training; Group 2 = Gratitude Journaling; Group 3 = Combined Intervention; Group $4=$ Control Group

EWB = Emotional Well-being (Subscale of MHC-SF); SWB = Social Well-being (Subscale of MHC-SF); PWB = Psychological Well-being (Subscale of MHC-SF); MHC Total = Mental Health Continuum Total (Overall well-being); SWLS = Satisfaction With Life Scale; PSS = Perceived Stress Scale. 
Table 2 Findings from ANCOVA for

Intervention Impact on

Dependent Variables

\begin{tabular}{lll}
\hline Dependent variables & \multicolumn{2}{l}{ Time 1- Time 2 } \\
\cline { 2 - 3 } & $F$ & $\begin{array}{l}\text { Partial } \\
\eta 2\end{array}$ \\
\cline { 2 - 3 } & & 0.02 \\
EWB & 1.82 & 0.05 \\
SWB & $4.28^{* *}$ & 0.01 \\
PWB & 0.53 & 0.01 \\
MHC Total & $2.97^{*}$ & 0.04 \\
SWLS & 0.84 & 0.01 \\
PSS & 1.49 & 0.02 \\
Meaning & 1.83 & 0.02 \\
Engagement & 0.86 & 0.01 \\
\hline
\end{tabular}

Note. $\mathrm{EWB}=$ Emotional Well-being (Subscale of MHC-SF); SWB = Social Well-being (Subscale of MHC-SF); PWB = Psychological Well-being $($ Subscale of MHC-SF $)$; MHC Total = Mental Health Continuum Total (Overall well-being); SWLS = Satisfaction With Life Scale; PSS = Perceived Stress Scale

Counterintuitively, subsequent pairwise group comparisons in both these cases suggested that the control group scored significantly better than the gratitude journaling group.

\section{Discussion}

Managing stress and its ill-effects is important for most people in the present times, particularly young people - children and adolescents who are at an impressionable developmental stage of life. Psychological interventions such as gratitude journaling and stress management training could be helpful in alleviating stress and enhacing well-being (e.g., Emmons \& McCullough, 2003; Foret et al., 2012; Froh et al., 2008; Isik \& Ergüner-Tekinalp, 2017; Nair \& Meera, 2014). The aim of the present study was to examine the efficacy of a gratitude journaling and stress management intervention (Flinchbaugh et al., 2012) among Indian school students. We did not find support for the hypothesis that participation in gratitude journaling, stress management training (or a combination of both) would result in gains in well-being as compared to a control group.

On the whole, significant intervention effect was seen on social well-being, and overall well-being. The effect sizes herein (see partial $\eta 2$ presented in the results) were small based on benchmarks suggested by Cohen (1988). Subsequent pairwise comparisons of adjusted means among the four groups on these two variables revealed significant difference only between gratitude journaling and the control group. In both these cases, the gratitude journaling group showed lower well-being than the control group. These findings seem to suggest that none of the intervention techniques were successful in bringing about statistically significant change in participants' perceived stress, meaningfulness, engagement, or life satisfaction. On the contrary, our findings imply that gratitude journaling may possibly have been counterproductive for the participants.

The present findings concur with Flinchbaugh et al. (2012) with respect to no effect on participants' perceived stress and life satisfaction. However, they differ from Flinchbaugh et al. in as far as the significant intervention effect on perceived classroom meaningfulness and engagement goes. Our findings also align with Hines and Scherer (2018) who reported no signifcant effects on college students' stress levels after mindfulness meditation and gratitude journaling. Nonetheless, many studies reviewed previously in this paper (e.g., Emmons \& McCullough, 2003; Froh et al., 2008; Isik \& ErgünerTekinalp, 2017) offer favorable evidence for gratitude journaling among students. Another gratitude intervention curriculum (Froh et al., 2014) that emphasized the socio-cognitive components of gratitude in addition to journaling was successful in enhancing well-being among Indian adolescents (Khanna \& Singh, 2016). This encourages greater focus on nature of activities used, a point addressed in the section on future recommendations ahead in this paper. Our findings also supplement extant literature that offers mixed evidence for stress management training in the classroom. While some studies have endorsed effectiveness of practicing stress management in the classroom (e.g., Foret et al., 2012; Kanji et al., 2006; Nair \& Meera, 2014), others (e.g., Hashim \& Zainol, 2015; Vierhaus et al., 2010) claimed otherwise. Plausible explanations for the present results are discussed ahead by examining the two fundamental intervention techniques at the heart of this study, i.e. gratitude journaling and stress management training.

\section{Potential Pitfalls of Gratitude Journaling}

An obvious reason for the apparent ineffectiveness of gratitude journaling among the present study participants emerged from their qualitative feedback for the exercise, collected at post-test. They expressed dislike for having to write during the program in general and for journaling in particular. Responses such as "I got so many worksheets that I got exhausted...", "It was boring - they should have more activities" gave us an insight into students' aversion to the journaling exercise (Khanna \& Singh, 2014). It appears that the psychological difficulties associated with journaling outweighed its intended benefits. This observation draws support from existing research that has noted some drawbacks associated with journal writing, despite its salient benefits (e.g. Crème, 2005; Dyment \& O’Connell, 2010; Epp, 2008; \& Mills, 2008). It is pertinent to mention here that the Indian school education system places preponderant emphasis on written work in a prescriptive and authoritarian manner (Rai, 2015). This could lead to students 
associating any form of writing with work that isn't instinctively pleasurable. Hence, completing a task which one finds onerous may actually have been a setback to the students' well-being in the present study.

\section{Mixed Effect of Stress Management Techniques}

Both Flinchbaugh et al. (2012) and the present study reported no statistically significant intervention effects on perceived stress among participants. Flinchbaugh and colleagues posited that the stress management practice in the program may have been insufficient to impact students' stress levels. In case of the present study too, it is quite likely that students did not supplement in-class practice of stress management techniques with further enagagement beyond the classroom sessions (although this was encouraged by the facilitator). Foret et al. (2012) reported similar concerns in their study of a classroom based relaxation-response curriculum. This idea is backed by research in the area of behaviour modification which suggests that at least six consecutive months of regular practice are required to inculcate a new activity into a person's routine behaviour (Center for Disease Control and Prevention, 2007).

In this study, constraints of space and ambient noise in the school classroom setting may also have influenced stress management training and its consequent impact on participants. These impediments reflect the challenges of real-world studies, similar to those characteristic of community-based participatory research (Wallerstein \& Duran, 2006). Review of qualitative feedback received from the participants at post-test revealed that many students perceived gains in terms of feeling relaxed and calm. While these findings are elaborated elsewhere (Khanna \& Singh, 2014), it is notable that they are in tune with the objective of the present study. Nevertheless, these perceived benefits reported by students were not mirrored in the quantitative results. This is akin to the findings reported by Conley et al. (2013a and b). In this regard, it has been found that absolute scales have weaker predictive validity (than relative scales) and may therefore be somewhat resistant to group differences and intervention impact. In fact, given that most outcome variables in this study were fairly fixed psychological features, standardised instruments may be limited in their ability to detect minute impact that may be observed during universal interventions involving a largely healthy sample (Chamberlain \& Zika, 1992; cf. Conley et al., 2013a and b; Pickering, 2002).

\section{Limitations and Future Recommendations}

It is imperative to interpret the study findings against the backdrop of some immanent limitations. While acknowledging the study limitations, this section also offers recommendations to overcome these in future research. First, taking cognizance of surrounding distractions that are a natural part of the young student classroom environment, further thought is needed to assess the feasibility of implementing interventions of this nature. Future studies may look at suitable modification of this intervention for greater student engagement in the Indian classroom context. Including more interactive and activitybased strategies may work better with younger participants such as the current study sample.

Next, the inability to monitor students' engagement (or lack thereof) with the intervention strategies outside the classroom was another limitation. Owing to budgetary and time constraints it was not within the purview of this study to track if participants practiced stress management exercises or journaling and whether regular/more frequent practice would have been associated with greater intervention gains. By extension, while this study was limited to classrooms, future research could aim to encompass the home context as well and assess multiple outcomes from different stakeholders (e.g. teachers, parents). This would additionally help to overcome the sole reliance on student self-report. Truskauskaitè-Kunevičienè et al. 2018 also recommend preventive youth interventions embedded in multiple contexts including family, school, and community.

Finally, participants in this study were passively assigned to activities determined by the researchers; a situation that is understood to hinder very favourable intervention outcomes and effect sizes (Sheldon \& Lyubomirsky, 2019). Future research could involve self-selected participants and encourage better person-activity fit to offer greater benefits (Lyubomirsky et al., 2011; Sheldon \& Lyubomirsky, 2019).

\section{Study Implications and Conclusion}

To sum up, the present study did not garner much support for the effectiveness of classroom based stress management and gratitude journaling practice among Indian adolescents. Nevertheless, it is important to not dismiss the value of these intervention strategies; but emphasize that a standard, invariable approach of utilizing them may not be the best way forward. Roy et al. (2019) endorsed the need for preventive interventions to support the cause of adolescent mental health in India. The present study was a step forward in this direction. Two widely recognized strategies (gratitude journaling and stress management training) were taken up and their impact explored in a relatively under researched demographic group (Indian adolescents). In fact, Schwartz and Baer (1991) posited that the aim of social validity lies beyond accumulating false praise for a program; it is about gathering relevant information about possible flaws, problems in implementation and perceptions about the program impact. To this effect, although our study did not report significant intervention gains, these findings build the case for contextually relevant programs to accrue greater benefit. Kistin and Silverstein (2015) also emphasize the utility of initial trials and pilot work in recognizing failure with a view to guide subsequent design and mitigate existing concerns with intervention implementation. The contribution of this work may be best 
summarized by Kim's (2019) emphasis on utility of replication failure in generating new research questions and improving the applicability of intervention research.

These findings can ladder up to the creation of customized intervention modules for research and practice among diverse populations. Towards this end, getting to know what does not work is just as important as establishing what does.

Acknowledgements We are grateful to Dr. Carol Flinchbaugh for permitting use and adaptation of this intervention, and helping with queries that emerged along the way.

Authors' Contributions Both authors were involved in all stages of this research from conceptualization till preparation of manuscript.
Data Availability May be made available upon request.

\section{Compliance with Ethical Standards}

Conflict of Interest On behalf of all authors, the corresponding author states that there is no conflict of interest.

Ethical Standards The study involves human participants. All procedures in this study were in accordance with the ethical standards of the institutional research committee, and with the 1964 Helsinki declaration and its later amendments. Informed consent was obtained from all individual participants included in the study, as well as their parents. Details have been provided in the manuscript.

Code Availability Not applicable.

\section{Appendix 1}

Table 3 Key Points of Adaptation in the Present Study Compared to Flinchbaugh et al. (2012)

\begin{tabular}{|c|c|c|c|}
\hline Criterion & Flinchbaugh et al. (2012) & Present Study & Rationale for adaptation \\
\hline Duration of intervention & 12 weeks & 8 weeks & $\begin{array}{l}\text { To fit the module within the schools' } \\
\text { academic timeline; is a usual practice } \\
\text { in community based research in school } \\
\text { settings (e.g., Foret et al., 2012) }\end{array}$ \\
\hline $\begin{array}{l}\text { Frequency of } \\
\text { introducing new } \\
\text { stress management } \\
\text { technique }\end{array}$ & Every 3 weeks & $\begin{array}{l}\text { Every } 2 \text { weeks } \\
\text { (each technique over two sessions: } \\
\text { 1- Introduction, } \\
\text { \& 2- Practice \& Reinforcement) }\end{array}$ & $\begin{array}{l}\text { In view of participants being younger } \\
\text { students at a different developmental } \\
\text { stage than those in the original study }\end{array}$ \\
\hline Medium of journaling & Online & Children friendly hard copy journal booklets & $\begin{array}{l}\text { Participants' age and logistics available } \\
\text { in participating schools }\end{array}$ \\
\hline Facilitator & $\begin{array}{l}\text { Different facilitators } \\
\text { across all four groups }\end{array}$ & $\begin{array}{l}\text { Common facilitator } \\
\text { across all four groups }\end{array}$ & $\begin{array}{l}\text { Recommended by Flinchbaugh et al. } \\
\text { (2012) in order to diminish the effect } \\
\text { of potential differences due to } \\
\text { different facilitators }\end{array}$ \\
\hline
\end{tabular}

\section{Appendix 2}

Table 4 Findings of CFA Along with Reference Values of Indices Used

\begin{tabular}{|c|c|c|c|c|c|}
\hline Measures Used & $\begin{array}{l}\text { RMSEA } \\
<0.10 \text { (MacCallum, } \\
\text { Browne, Sugawara, 1996) }\end{array}$ & $\begin{array}{l}\text { NNFI } \\
>0.90 \text { (Garver } \\
\& \text { Mentzer, 1999) }\end{array}$ & $\begin{array}{l}\text { GFI } \\
>0.90 \text { (Tabachnick } \\
\& \text { Fidell, 2007) }\end{array}$ & $\begin{array}{l}\text { CFI } \\
\geq 0.95 \text { (Hu \& Bentler, 1999) }\end{array}$ & $\begin{array}{l}X^{2} / \mathrm{df} \\
<5 \\
\text { (Garver \& Mentzer, 1999) }\end{array}$ \\
\hline MHC-SF & 0.04 & 0.97 & 0.97 & 0.97 & 2.64 \\
\hline $\begin{array}{l}\text { SWLS } \\
\text { PSS }\end{array}$ & $\begin{array}{l}0.07 \\
0.09\end{array}$ & $\begin{array}{l}0.94 \\
0.92\end{array}$ & $\begin{array}{l}0.98 \\
0.91\end{array}$ & $\begin{array}{l}0.97 \\
0.95\end{array}$ & $\begin{array}{l}1.65 \\
3.55\end{array}$ \\
\hline Meaningfulness & 0.1 & 0.95 & 0.91 & 0.96 & 3.70 \\
\hline Engagement & 0.1 & 0.75 & 0.88 & 0.81 & 4.56 \\
\hline
\end{tabular}

Note. RMSEA = root mean squared approximation of error; NNFI = non-normed fit index; GFI = goodness of fit index; CFI = comparative fit index; $X^{2} /$ $\mathrm{df}=$ ratio of chi-square to degrees of freedom; MHC-SF $=$ Mental Health Continuum- Short Form; SWLS = Satisfaction with Life Scale; PSS = Perceived Stess Scale. Models are evaluated by observing more than one indicator. Different scholars recommend different indices 


\section{References}

Alborzkouh, P., Nabati, M., Zainali,M., Abed, Y., \& Shahgholy Ghahfarokhi, F. (2015). A review of the effectiveness of stress management skills training on academic vitality and psychological wellbeing of college students. Journal of Medical Life, 8(4), 39-44.

Anand, U., \& Sharma, M. P. (2011). Impact of a mindfulness-based stress reduction program on stress and well-being in adolescents: A study at a school setting. Journal of Indian Association of Child \& Adolescent Mental Health, 7(3), 73-97.

Arun, P., \& Chavan, B. S. (2009). Stress and suicidal ideas in adolescent students in Chandigarh. Indian Journal of Medical Science, 63(7), 281-287. https://doi.org/10.4103/0019-5359.55112.

Biegel, G. M., Brown, K. W., Shapiro, S. L., \& Schubert, C. M. (2009). Mindfulness-based stress reduction for the treatment of adolescent psychiatric outpatients: A randomized clinical trial. Journal of Consulting and Clinical Psychology, 77(5), 855-866. https://doi. org/10.1037/a0016241.

Broderick, P., \& Metz, S. (2009). Learning to BREATHE: A pilot trial of a mindfulness curriculum for adolescents. Advances in School Mental Health Promotion, 2, 35-46. https://doi.org/10.1080/ 1754730X.2009.9715696.

Center for Disease Control and Prevention. (2007). Transtheoretical stage model. Retrieved on August 14, 2013 from http://www.cdc. gov/hiv/topics/prev_prog/acdp/intervention/

Chamberlain, K., \& Zika, S. (1992). Stability and change in subjective well-being over short time periods. Social Indicators Research, 26(2), 101-117. https://doi.org/10.1007/BF00304394.

Chhabra, G. S., \& Sodhi, M. K. (2011). Factors contributing to psycho-social ill-health in male adolescents. Online Journal of Health \& Allied Sciences, 10(3), 2 http://www.ojhas.org/issue39/2011-3-2.htm.

Chinaveh, M. (2013). The effectiveness of multiple stress management intervention on the level of stress, and coping responses among Iranian students. Procedia - Social and Behavioral Sciences, 84, 593-600. https://doi.org/10.1016/j.sbspro.2013.06.610.

Cohen, S., Kamarck, T., \& Mermelstein, R. (1983). A global measure of perceived stress. Journal of Health and Social Behavior, 24(4), 385-396. https://doi.org/10.2307/2136404.

Cohen, J. (1988). Statistical power analysis for the behavioral sciences. Routledge Academic.

Collins, S., Woolfson, L. M., \& Durkin, K. (2014). Effects on coping skills and anxiety of a universal school-based mental health intervention delivered in Scottish primary schools. School Psychology International, 35(1), 85-100. https://doi.org/10.1177/ 0143034312469157.

Conley, C. S., Durlak, J. A., \& Dickson, D. A. (2013a). An evaluative review of outcome research on universal mental health promotion and prevention programs for higher education students. Journal of American College Health, 61(5), 286-301. https://doi.org/10.1080/ 07448481.2013 .802237$.

Conley, C. S., Travers, L. V., \& Bryant, F. B. (2013b). Promoting psychosocial adjustment and stress management in first-year college students: The benefits of engagement in a psychosocial wellness seminar. Journal of American College Health, 61(2), 75-86. https://doi.org/10.1080/07448481.2012.754757.

Creme, P. (2005). Should student learning journals be assessed? Assessment \& Evaluation in Higher Education, 30(3), 287-296. https://doi.org/10.1080/02602930500063850.

Deb, S., Strodl, E., \& Sun, H. (2015). Academic stress, parental pressure, anxiety and mental health among Indian high school students. International Journal of Psychology and Behavioral Science, 5(1), 26-34. https://doi.org/10.5923/j.ijpbs.20150501.04.

Diener, E., Emmons, R. A., Larsen, R. J., \& Griffin, S. (1985). The satisfaction with life scale. Journal of Personality Assessment, 49(1), 71-75. https://doi.org/10.1207/s15327752jpa4901_13.
Dyment, J. E., \& O’Connell, T. S. (2003). “Journal writing is something we have to learn on our own" - the results of a focus group discussion with recreation students. Schole: A Journal of Leisure Studies and Recreation Education, 18(1), 23-28.

Dyment, J. E., \& O'Connell, T. S. (2010). The quality of reflection in student journals: A review of limiting and enabling factors. Journal of Innovative Higher Education, 35(4), 233-244. https://doi.org/10. 1007/s10755-010-9143-y.

Edwards, M., Adams, E. M., Waldo, M., Hadfield, O. D., \& Biegel, G. M. (2014). Effects of a mindfulness group on Latino adolescent students: Examining levels of perceived stress, mindfulness, self-compassion, and psychological symptoms. Journal for Specialists in Group Work, 39(2), 145-163. https://doi.org/10.1080/01933922. 2014.891683.

Emmons, R. A., \& McCullough, M. E. (2003). Counting blessings versus burdens: An experimental investigation of gratitude and subjective well-being in daily life. Journal of Personality and Social Psychology, 84(2), 377-389. https://doi.org/10.1037/0022-3514. 84.2.377.

Epp, S. (2008). The value of reflective journaling in undergraduate nursing education: A literature review. International Journal of Nursing Studies, 45(9), 1379-1388. https://doi.org/10.1016/j.ijnurstu.2008. 01.006 .

Fazel, M., Patel, V., Thomas, S., \& Tol, W. (2014). Mental health interventions in schools in low-income and middle-income countries. The Lancet. Psychiatry, 1(5), 388-398. https://doi.org/10.1016/ S2215-0366(14)70357-8.

Ferreira-Vorkapic, C., Feitoza, J. M., Marchioro, M., Simões, J., Kozasa, E., \& Telles, S. (2015). Are there benefits from teaching yoga at schools? A systematic review of randomized control trials of yogabased interventions. Evidence-based complementary and alternative medicine : eCAM, 2015, 345835-345817. https://doi.org/10.1155/ $2015 / 345835$.

Fisher, J., Cabral de Mello, M., Izutsu, T., Vijayakumar, L., Belfer, M., \& Omigbodun, O. (2011). Adolescent Mental Health in ResourceConstrained Settings: A review of the evidence of the nature, prevalence and determinants of common mental health problems and their management in primary health care. The International journal of social psychiatry, 57(1 Suppl), v-116. https://doi.org/10.1177/ 0020764010397628.

Flett, G. L., \& Hewitt, P. L. (2013). Disguised distress in children and adolescents "flying under the radar": Why psychological problems are underestimated and how schools must respond. Canadian Journal of School Psychology, 28(1), 12-27. https://doi.org/10. $1177 / 0829573512468845$.

Flinchbaugh, C. L., Moore, E. W., Chang, Y. K., \& May, D. R. (2012). Student well-being interventions: The effects of stress management techniques and gratitude journaling in the management education classroom. Journal of Management Education, 36(2), 191-219. https://doi.org/10.1177/1052562911430062.

Foret, M. M., Scult, M., Wilcher, M., Chudnofsky, R., Malloy, L., Hasheminejad, N., \& Park, E. R. (2012). Integrating a relaxation response-based curriculum into a public high school in Massachusetts. Journal of Adolescence, 35(2), 325-332. https:// doi.org/10.1016/j.adolescence.2011.08.008.

Froh, J. J., Sefick, W. J., \& Emmons, R. A. (2008). Counting blessings in early adolescents: An experimental study of gratitude and subjective well-being. Journal of School Psychology, 46(2), 213-233. https:// doi.org/10.1016/j.jsp.2007.03.005.

Froh, J. J., Bono, G., Fan, J., Emmons, R. A., Henderson, K., Harris, C., Leggio, H., \& Wood, A. (2014). Nice thinking! An educational intervention that teaches children how to think gratefully [special issue: Theoretical frameworks in school psychology intervention research: Interdisciplinary perspectives and future directions]. School Psychology Review, 43(2), 132-152. https://doi.org/10. 1080/02796015.2014.12087440. 
Garver, M. S., \& Mentzer, J. T. (1999). Logistics research methods: Employing structural equation modelling to test for construct validity. Journal of Business Logistics, 20(1), 33-57.

Gilman, R., Huebner, E. S., \& Furlong, M. J. (2014). Toward a science and practice of positive psychology in schools: A conceptual framework. In M. J. Furlong, R. Gilman, \& E. S. Huebner (Eds.), Educational psychology handbook series. Handbook of positive psychology in schools (pp. 3-11) Routledge/Taylor \& Francis Group.

Gururaj, G., Varghese, M., Benegal, V., Rao, G. N., Pathak, K., Singh, L. K.,. .. NMHS Collaborators Group. (2016). National Mental Health Survey of India, 2015-16: Prevalence, patterns and outcomes (Publication No. 129). National Institute of Mental Health and Neurosciences. http://indianmhs.nimhans.ac.in/Docs/Report2.pdf

Hashim, H. A., \& Zainol, N. A. (2015). Changes in emotional distress, short term memory, and sustained attention following 6 and 12 sessions of progressive muscle relaxation training in 10-11 years old primary school children. Psychology, Health \& Medicine, 20(5), 623-628.10.1080/13548506 2014.1002851.

Hines, S., \& Scherer, L. (2018, March). Effect of mindful meditation and gratitude journaling on college students stress and well-being over time. In Paper presented at $10^{\text {th }}$ annual student research and creative activity fair at the University of Nebraska. Omaha: United States.

Hossain, M. M., \& Purohit, N. (2019). Improving child and adolescent mental health in India: Status, services, policies, and way forward. Indian Journal of Psychiatry, 61(4), 415-419. https://doi.org/10. 4103/psychiatry.IndianJPsychiatry_217_18.

Hu, L., \& Bentler, P. M. (1999). Cut-off criteria for fit indexes in covariance structure analysis: Conventional criteria versus new alternatives. Structural Equation Modelling, 6, 1-55.

Ișik, S., \& Ergüner-Tekinalp. (2017). The effects of gratitude journaling on Turkish first year college students' college adjustment, life satisfaction and positive affect. International Journal for the Advancement of Counselling, 39(2), 164-175. https://doi.org/10. 1007/s10447-017-9289-8.

Jayashree, K., Mithra, P. P., Nair, M. K., Unnikrishnan, B., \& Pai, K. (2018). Depression and anxiety disorders among school going adolescents in an urban area of South India. Indian Journal of Community Medicine, 43, 28-32. https://doi.org/10.4103/ijcm. IJCM_209_18.

Kanji, N., White, A., \& Ernst, E. (2006). Autogenic training to reduce anxiety in nursing students: Randomized controlled trial. Journal of Advanced Nursing, 53, 729-735. https://doi.org/10.1111/j.13652648.2006.03779.x.

Keogh, E., Bond, F. W., \& Flaxman, P. E. (2006). Improving academic performance and mental health through a stress management intervention: Outcomes and mediators of change. Behaviour Research and Therapy, 44(3), 339-357. https://doi.org/10.1016/j.brat.2005. 03.002

Keyes, C. L. (2005). Mental illness and/or mental health? Investigating axioms of the complete state model of health. Journal of Consulting and Clinical Psychology, 73(3), 539-548. https://doi.org/10.1037/ 0022-006X.73.3.539.

Khanna, P., \& Singh, K. (2014). Perceived effectiveness of positive psychology intervention programs among north Indian school students. International Research Journal of Human Resources and Social Sciences, 1(7), 1-17.

Khanna, P., \& Singh, K. (2016). Effect of gratitude educational intervention on well-being indicators among north Indian adolescents. Contemporary School Psychology, 20(4), 305-314. https://doi.org/ 10.1007/s40688-016-0087-9.

Khanna, P., \& Singh, K. (2019). Do All Positive Psychology Exercises Work for Everyone? Replication of Seligman et al.'s (2005) Interventions among Adolescents. Psychological Studies, 64(1), 110. https://doi.org/10.1007/s12646-019-00477-3.
Kieling, C., Baker-Henningham, H., Belfer, M., Conti, G., Ertem, I., Omigbodun, O., Rohde, L. A., Srinath, S., Ulkuer, N., \& Rahman, A. (2011). Child and adolescent mental health worldwide: Evidence for action. Lancet (London, England), 378(9801), 1515-1525. https://doi.org/10.1016/S0140-6736(11)60827-1.

Kim, J. S. (2019). Making every study count: Learning from replication failure to improve intervention research. Educational Researcher, 48(9), 599-607. https://doi.org/10.3102/0013189X19891428.

Kistin, C., \& Silverstein, M. (2015). Pilot studies: A critical but potentially misused Ccomponent of interventional research. JAMA, 314(15), 1561-1562. https://doi.org/10.1001/jama. 2015.10962 .

Kuyken, W., Weare, K., Ukoumunne, O. C., Vicary, R., Motton, N., Burnett, R., Cullen, C., Hennelly, S., \& Huppert, F. (2013). Effectiveness of the mindfulness in schools Programme: Nonrandomised controlled feasibility study. The British journal of psychiatry : the journal of mental science, 203(2), 126-131. https://doi. org/10.1192/bjp.bp.113.126649.

Lau, N., \& Hue, M. (2011). Preliminary outcomes of a mindfulness-based programme for Hong Kong adolescents in schools: Well-being, stress and depressive symptoms. International Journal of Children's Spirituality, 16(4), 315-330. https://doi.org/10.1080/ 1364436X.2011.639747.

Liehr, P., \& Diaz, N. (2010). A pilot study examining the effect of mindfulness on depression and anxiety for minority children. Archives of Psychiatric Nursing, 24(1), 69-71. https://doi.org/10.1016/j.apnu. 2009.10.001.

Lohaus, A., Klein-Heßling, J., Vögele, C., \& Kuhn-Hennighausen, C. (2001). Psychophysiological effects of relaxation training in children. British Journal of Health Psychology, 6(2), 197-206. https:// doi.org/10.1348/135910701169151.

Lyubomirsky, S., Dickerhoof, R., Boehm, J. K., \& Sheldon, K. M. (2011). Becoming happier takes both a will and a proper way: An experimental longitudinal intervention to boost well-being. Emotion (Washington, D.C.), 11(2), 391-402. https://doi.org/10.1037/ a0022575.

MacCallum, R. C., Browne, M. W., \& Sugawara, H. M. (1996). Power analysis and determination of sample size for covariance structure modeling. Psychological Methods, 1(2), 130-149. https://doi.org/ 10.1037/1082-989X.1.2.130.

Malhotra, S., \& Patra, B. N. (2014). Prevalence of child and adolescent psychiatric disorders in India: A systematic review and meta-analysis. Child and Adolescent Psychiatry and Mental Health, 8, 22-30. https://doi.org/10.1186/1753-2000-8-22.

May, D. R. (2004, July). The flourishing of the human spirit at work: Toward an understanding of the determinants and outcomes of experienced meaningfulness at work. In Paper presented at the 2nd European conference on positive psychology. Verbania Pallanza: Italy.

May, D. R., Gilson, R. L., \& Harter, L. M. (2004). The psychological conditions of meaningfulness, safety and availability and the engagement of the human spirit at work. Journal of Occupational and Organizational Psychology, 77(1), 11-37. https://doi.org/10. 1348/096317904322915892.

Mills, R. (2008). "It's just a nuisance": Improving college student reflective journal writing. College Student Journal, 42(2), 684-690.

Nair, S., Ganjiwale, J., Kharod, N., Varma, J., \& Nimbalkar, S. M. (2017). Epidemiological survey of mental health in adolescent school children of Gujarat, India. BMJ Paediatrics Open. https:// doi.org/10.1136/bmjpo-2017-000139.

Nair, P. P., \& Meera, K. P. (2014). Effectiveness of progressive muscle relaxation in reducing academic stress of secondary schools students of Kerala. IOSR Journal of Humanities and Social Science, 19(8), 29-32 http://www.iosrjournals.org/iosr-jhss/papers/Vol19-issue8/ Version-1/F019812932.pdf. 
Neff, K. D., \& McGehee, P. (2010). Self-compassion and psychological resilience among adolescents and young adults. Self and Identity, 9(3), 225-240. https://doi.org/10.1080/15298860902979307.

Nidich, S., Mjasiri, S., Nidich, R., Rainforth, M., Grant, J., Valosek, L, ..Zigler, R. (2011). Academic achievement and transcendental meditation: A study with at-risk urban middle school students. Education, 131, 556-564.

Office of the Registrar General \& Census Commissioner India. (2011). Census data New Delhi: Ministry of Home Affairs. Government of India, 2011 Available from: http://www.censusindia.gov.in/ 2011 census/PCA/PCA_Highlights/pca_highlights_file/India/ Chapter-1.pdf.

Parikh, R., Sapru, M., Krishna, M., Cuijpers, P., Patel, V., \& Michelson, D. (2019). "It is like a mind attack": Stress and coping among urban school-going adolescents in India. BMC Psychology, 7, 31. https:// doi.org/10.1186/s40359-019-0306-z.

Patel, V., Flisher, A. J., Hetrick, S., \& McGorry, P. (2007). Mental health of young people: A global public-health challenge. Lancet (London, England), 369(9569), 1302-1313. https://doi.org/10.1016/S01406736(07)60368-7.

Patton, G. C., Sawyer, S. M., Santelli, J. S., Ross, D. A., Afifi, R., Allen, N. B., Arora, M., Azzopardi, P., Baldwin, W., Bonell, C., Kakuma, R., Kennedy, E., Mahon, J., McGovern, T., Mokdad, A. H., Patel, V., Petroni, S., Reavley, N., Taiwo, K., Waldfogel, J., Wickremarathne, D., Barroso, C., Bhutta, Z., Fatusi, A. O., Mattoo, A., Diers, J., Fang, J., Ferguson, J., Ssewamala, F., \& Viner, R. M. (2016). Our future: A lancet commission on adolescent health and well-being. Lancet (London, England), 387(10036), 2423-2478. https://doi.org/10.1016/S0140-6736(16)00579-1.

Pickering, R. (2002). Statistical aspects of measurement in palliative care. Palliative Medicine, 16, 359-364. https://doi.org/10.1191/ 0269216302pm579xx.

Prabhu, S. G., \& Shekhar, R. (2017). Resilience and perceived social support among school-going adolescents in Mangaluru. Indian Journal of Social Psychiatry, 33(4), 359-364. https://doi.org/10. 4103/ijsp.ijsp 10816.

Rai, M. (2015). Writing in Indian schools: The product priority. Language and Language Teaching, 4(1), 32-36.

Rashedi, R. N., Weakley, M., Malhi, A., Wajanakunakorn, M., \& Sheldon, J. (2020). Supporting positive behaviors through yoga: An exploratory study. The Journal of Positive Psychology, 15(1), 122-128. https://doi.org/10.1080/17439760.2019.1579364.

Rentala, S., Nayak, R. B., Patil, S. D., Hegde, G. S., \& Aladakatti, R. (2019). Academic stress among Indian adolescent girls. Journal of education and health promotion, 8, 158. https://doi.org/10.4103/ jehp.jehp_116_19.

Roy, K., Shinde, S., Sarkar, B. K., Malik, K., Parikh, R., \& Patel, V. (2019). India's response to adolescent mental health: A policy review and stakeholder analysis. Social Psychiatry and Psychiatric Epidemiology, 54(4), 405-414. https://doi.org/10.1007/s00127018-1647-2.

Sandal, R. K., Goel, N. K., Sharma, M. K., Bakshi, R. K., Singh, N., \& Kumar, D. (2017). Prevalence of depression, anxiety and stress among school going adolescents in Chandigarh. Journal of Family Medicine and Primary Care, 6(2), 405-410. https://doi.org/10. 4103/2249-4863.219988.

Schnitker, S. A., \& Richardson, K. L. (2018). Framing gratitude journaling as prayer amplifies its hedonic and eudaimonic well-being, but not health, benefits. The Journal of Positive Psychology, 14, 1-13. https://doi.org/10.1080/17439760.2018.1460690.
Schonert-Reichl, K. A., \& Lawlor, M. S. (2010). The effects of a mindfulness-based education program on pre- and early adolescents' well-being and social and emotional competence. Mindfulness, 1(3), 137-151. https://doi.org/10.1007/s12671-0100011-8.

Schwartz, I. S., \& Baer, D. M. (1991). Social validity assessments: Is current practice state of the art? Journal of Applied Behavior Analysis, 24(2), 186-212. https://doi.org/10.1901/jaba.1991.24189.

Sheldon, K. M., \& Lyubomirsky, S. (2019). Revisiting the sustainable happiness model and pie chart: Can happiness be successfully pursued? The Journal of Positive Psychology. Advance online publication., 1-10. https://doi.org/10.1080/17439760.2019. 1689421.

Shi, G., \& Zhu, W. (2008). The intervention of gratitude and subjective well-being for junior middle school students. Psychological Exploration. http://en.cnki.com.cn/Article_en/CJFDTOTALOXLY200803010.htm

Tabachnick, B. G., \& Fidell, L. S. (2007). Using multivariate statistics (5th ed.).

Tran, O. K., Gueldner, B. A., \& Smith, D. (2014). Building resilience in schools through social and emotional learning. In M. Furlong, R. Gilman, \& E. S. Huebner (Eds.), Handbook of positive psychology in schools (2nd ed., pp. 298-312). Routledge.

Truskauskaitè-Kunevičienè, I., Romera, E., Ortega-Ruiz, R., \& Žukauskienè, R. (2018). Promoting positive youth development through a school-based intervention program try volunteering. Current Psychology., 39, 705-719. https://doi.org/10.1007/ s12144-018-9790-1.

Vhavle, S., Rao, M. R., Manjunath, N. K., \& Ram, A. R. (2017). Effects of a yoga program on health, behaviour and learning ability in school children: A single arm observational study. International Journal of Complementary \& Alternative Medicine, 5(1), 00138. https://doi.org/10.15406/ijcam.2017.05.00138.

Vierhaus, M., Maass, A., Fridrici, M., \& Lohaus, A. (2010). Effects of a school-based stress prevention program on adolescents in different phases of behavioural change. Educational Psychology: An International Journal of Experimental Educational Psychology, 30, 465-480. https://doi.org/10.1080/01443411003724624.

Wallerstein, N. B., \& Duran, B. (2006). Using community-based participatory research to address health disparities. Health Promotion Practice, 7(3), 312-323. https://doi.org/10.1177/ 1524839906289376.

Wang, D., \& Hagins, M. (2016). Perceived Benefits of Yoga among Urban School Students: A Qualitative Analysis. Evidence-Based Complementary and Alternative Medicine, 2016, 7-7. https://doi. org/10.1155/2016/8725654.

Wilhsson, M., Svedberg, P., Högdin, S., \& Nygren, J. M. (2017). Strategies of adolescent girls and boys for coping with schoolrelated stress. The Journal of School Nursing, 33(5), 374-382. https://doi.org/10.1177/1059840516676875.

Wit, E. E., Bunders-Aelen, J., \& Regeer, B. (2016). Reducing stress in youth: A pilot-study on the effects of a university-based intervention program for university students in Pune, India. Journal of Educational and Developmental Psychology, 6(2), 53. https://doi. org/10.5539/jedp.v6n2p53.

Publisher's Note Springer Nature remains neutral with regard to jurisdictional claims in published maps and institutional affiliations. 